\title{
COMPORTAMENTO DO CONSUMIDOR DE CARNE DE FRANGO: UMA ANÁLISE DO CONSUMO E DA COMERCIALIZAÇÃO EM PARAGOMINAS-PA
}

\section{BEHAVIOR OF CHICKEN MEAT CONSUMER: AN ANALYSIS OF CONSUMPTION AND MARKETING IN PARAGOMINAS-PA}

\author{
Fabrini Quadros Borges \\ UFSCAR \\ Belém, PA, Brasil \\ E-mail: masterborges@bol.com.br

\section{Fabricio Quadros Borges} \\ Professor do Programa de Doutorado em Administração da Unama \\ Belém, PA, Brasil \\ E-mail: posdoctorborges@gmail.com \\ João Guimaraes Pinheiro \\ UEPA - Universidade do Estado do Pará \\ Belém, PA, Brasil \\ E-mail: vatraz@yahoo.com.br
}

Professor do Quadro Permanente da UEPA - Universidade do Estado do Pará e Doutorando em Engenharia da Produção pela

\section{RESUMO}

A investigação possui o objetivo de contribuir a proposição de estratégias mercadológicas para o setor de carnes de frango no município paraense de Paragominas e, para tanto, precisar-se-ia conhecer o comportamento do consumidor final desse município. A investigação questiona qual a percepção de valor no setor de carnes de frango pelos consumidores no município de Paragominas. A necessidade de conhecer o comportamento do consumidor final de Paragominas vincula-se a possibilidade de favorecimento estratégico do setor de carnes de frango naquele município e de beneficiamento, por meio de aprimoramentos, ao longo da cadeia de modo a contribuir para o aumento da competitividade do setor. A metodologia empregada foi de natureza quantitativa do tipo survey composta por 390 entrevistas de maneira a aplicar o teste $\mathrm{G}$ a partir do fator socioeconômico. $\mathrm{O}$ estudo concluiu que quanto maior o poder de consumo de determinada fatia de consumidores maior será a procura por qualidade

Palavras-chave: Comportamento do Consumidor. Consumo. Comercialização. Preferência. Carne de frango.

Data de submissão: 5 de maio de 2015.

\section{ABSTRACT}

The research aims to contribute to the proposal of marketing strategies for the poultry meat sector in the municipality of Paragominas, and for that, it would be necessary to know the behavior of the final consumer of this municipality. The research questions the perception of value in the chicken meat sector by consumers in the municipality of Paragominas. The need to know the behavior of the final consumer of Paragominas is linked to the possibility of strategic favoring of the poultry meat sector in that municipality and of beneficiation, through improvements, along the chain in order to contribute to the increase of the competitiveness of the sector. The methodology used was of a quantitative nature of the survey type composed of 390 interviews in order to apply the $G$ test from the socioeconomic factor. The study concluded that the higher the consumption power of a certain share of consumers, the greater the demand for quality.

Keywords Consumer Behavior. Consumption. Commercialization. Preference. Chicken. 


\section{INTRODUÇÃO}

O comportamento humano em relação a um determinado produto ou serviço decorre da motivação do indivíduo diante dos bens e serviços colocados a sua disposição. Em vista disso, as empresas que pretendem ser competitivas devem fortalecer também suas cadeias de produção agroindustrial atentando para os fatores que influenciam a compra do produto por unidade familiar ou por um grupo de consumidores. O processo de aumento da competitividade constitui-se como fator para maximizar as escolhas dos consumidores. Neste processo é importante destacar que: as quantidades ofertadas, diversificação de produtos substitutos e o número de ofertantes, são fundamentais para fortalecer a competitividade.

É crescente o interesse pela investigação do comportamento do consumidor de carnes no Brasil e o papel do sistema agroindustrial de carnes, notadamente a bovina e a de frango, é cada vez mais objeto de interpretações e avaliações científicas (MAZZUCHETTI e BATALHA, 2004; NUNES e CASTRO, 2007; RODRIGUES; LIMA-FILHO; PEREIRA, 2008; VELHO, 2009; OLIVEIRA, A. P. de et al., 2015; TONI, et al., 2015; AGUIAIS e FIGUEIREDO, 2015; GARCIA, et al., 2017; FIGUEIREDO JUNIOR, et al., 2017). Na tentativa de avançar nas pesquisas quanto a estudos de campo com relação ao comportamento do consumidor brasileiro, estes estudos observam fatores como o preço, poder aquisitivo, local de compra, sabor e maciez, aspectos nutricionais, influência da imagem e percepção de valor, perfil de consumo e aspectos ligados às condições higiênicas, e sanitárias do processamento e comercialização de carnes no país.

Não é por acaso que estes estudos, particularmente sobre o setor de carnes de frango, cada vez mais diversificam seus focos de análise. A produção brasileira de carne de frango em 2016 foi de 12,90 milhões de toneladas (ABPA, 2017). Em 2017, verifica-se que mais de 150 mercados são importadores da carne de frango brasileira. Pelos portos do país, são quase 4 milhões de toneladas embarcadas anualmente, quase um terço de tudo o que se produz no país (ABPA, 2017).

As conexões que se verificam entre a produção e o consumo de alimentos são determinadas por elementos de natureza social, econômica, tecnológica, institucional, cultural e nutricional, os quais revelam os meandros a cerca das necessidades dos consumidores (AGUIAIS e FIGUEIREDO, 2015). Observa-se que na maioria dos trabalhos desenvolvidos no Brasil privilegia a produção ou o abastecimento, sendo poucos os dados disponíveis sobre o consumo alimentar. Sendo assim, reforça-se a necessidade da realização de pesquisas sistemáticas que cuidem da observação direta dos vários agentes sociais, tendo o consumidor como objeto central da cadeia agroalimentar. Questionamentos sobre consumo, mudanças, percepções, representações, gostos e práticas, ou seja, sobre as estratégias alimentares, poderiam revelar os vários aspectos relacionados à alimentação para diferentes grupos socioeconômicos. Além disso, do ponto de vista da oferta, poderiam ser analisadas as estratégias da produção e da distribuição e sua repercussão junto aos consumidores, assim como o papel das políticas no fenômeno de substituições alimentares e na introdução de novos hábitos de consumo.

Diante deste contexto, este estudo pretende questionar: qual a percepção de valor no setor de carnes de frango pelos consumidores no município de Paragominas? A compreensão dos meandros desta percepção de valor pode determinar aprimoramentos ao longo da cadeia, dessa forma, contribuir para aumentar a competitividade do setor. 
Assim, o objetivo geral deste estudo é o de contribuir a proposição de estratégias mercadológicas para o setor de carnes de frango no município de Paragominas e, para tanto, precisar-se-ia conhecer o comportamento do consumidor final desse município. Para isso tentou atender os objetivos específicos: caracterizar o perfil socioeconômico dos consumidores finais de carne de frango no município de Paragominas; investigar os hábitos de consumo do consumidor para carne de frango; identificar o grau de conhecimento nutricional da carne em questão por parte do consumidor final; e investigar as percepções dos consumidores sobre os atributos de qualidade da carne de frango.

O estudo se justifica: pela necessidade de conhecer o comportamento do consumidor final de Paragominas, de maneira a favorecer possibilidades estratégicas para o setor de carnes de frango naquele município paraense e pela utilidade em entender a dinâmica de percepção de valor neste segmento na intenção de fornecer aprimoramentos pontuais ao longo da cadeia e assim contribuir ao aumentar da competitividade do setor.

\section{REFERENCIAL TEÓRICO}

A contribuição para a proposição de estratégias mercadológicas para o setor de carnes de frango vincula-se diretamente a necessidade de compreensão dos meandros que envolvem o comportamento do consumidor. Conhecer o comportamento do consumidor condiciona à organização a adoção da melhor estratégia de marketing, uma vez que a satisfação do cliente deve ser foco prioritário (SOLOMON, 2016).

O comportamento do consumidor constitui-se como o estudo dos processos envolvidos quando indivíduos ou grupos selecionam, compram, usam ou dispõem de produtos, serviços, ideias ou experiências para satisfazer necessidades e desejos (SOLOMON, 2016). Este campo de estudo é definido como as atividades físicas e mentais realizadas por clientes de bens de consumo e industriais que resultam em decisões e ações, como comprar e utilizar produtos e serviços, bem como pagar por eles (SHETH; 2001).

Os estilos de vida dos consumidores são movidos pela associação com grupos dentro da sociedade global (SOLOMON, 2016). De acordo com Solomon (2016), estes grupos são conhecidos como subculturas, cujos componentes compartilham crenças e experiências comuns que os separam dos outros (SOLOMON, 2016). Ainda segundo o autor, todo consumidor pertence a várias subculturas. Essas associações podem ser baseadas em similaridades de idade, raça ou histórico étnico, local de residência ou mesmo uma forte identificação com uma atividade ou forma de arte (SOLOMON, 2016).

De acordo com Sheth et al. (2001), estudar o comportamento do consumidor equivale a compreender as pessoas em seu papel de clientes, isto é, verificar que produtos elas compram, como elas os compram, como os pagam e qual sua experiência com eles. Essas perguntas determinam se o tipo de consumidor representado por uma pessoa estaria nas perspectivas do produto ou serviço ofertado pela organização, que tipo de alterações no projeto dos determinados produtos ou serviços poderiam atrair essa pessoa ou o tipo de clientes que ela representa, como esse produto ou serviço the poderia ser oferecido e ainda que valor o produto poderia possuir para ela (SHETH et. al., 2001).

O comportamento do Consumidor é definido como as atividades físicas e mentais realizadas por clientes de bens de consumo e industriais que resultam em decisões e ações, como comprar e utilizar produtos e serviços, bem como pagar por eles (SHETH et. al., 2001). Assim, a definição proposta de comportamento do cliente inclui inúmeras atividades e muitos papéis que os consumidores podem adotar. 
Para Vargas (2010), um dos estudos mais relevantes da área do marketing é o comportamento do consumidor. São diversas as nuances que envolvem o comportamento do consumidor na medida em que tanto características extrínsecas, do ambiente, quanto intrínsecas, como motivação e idade, podem ajudar a compor este perfil de comportamento (SCHIFFMAN, e KANUK, 2000; KOTLER, 2007).

$O$ estudo do comportamento do consumidor consiste numa forma de obtenção de informações importantes para o desenvolvimento de novos produtos, para a realização de inovações em suas características, para auxílio em decisões sobre política de preços, bem como para identificar as alternativas mais interessantes em termos de canais de distribuição e publicidade (CHEUNG, 2007).

Segundo Pinheiro et al. (2006), os fatores de influência no comportamento de compra são: fatores psicológicos - estão compreendidos motivação, percepção, memória, aprendizagem, estilo de vida, personalidade, entre outros fatores intrínsecos; fatores socioculturais - compõe-se de família, cultura, classe social e demais questões relacionadas aos grupos de referência; e fatores situacionais - abrangem as diversas condições momentâneas ocorridas durante o processo de decisão de compra.

Segundo Limeira (2009), diversos foram os psicólogos motivacionais que possibilitaram explicar as motivações humanas. Um dos mais conhecidos é Abraham Maslow, que desenvolveu o modelo da hierarquia das necessidades em cinco níveis de necessidades: fisiológicas, de segurança, de sociabilidade, de estima e de auto-realização. De acordo com Limeira (2009): as necessidades fisiológicas compreendem necessidades básicas para a sustentação da existência, como comida, água, abrigo, sono e sexo; as necessidades de segurança equivalem à condição de estar livre do perigo físico e do medo da perda do emprego, do abrigo e estabilidade; as necessidades de sociabilidade ocorrem na medida em que os indivíduos possuem a necessidade de se sentirem aceitos e pertencentes a um determinado grupo; as necessidades de estima compreendem a demanda por estima e respeito; e a necessidade de auto realização que equivale ao desejo de maximizar seu potencial, realizar tudo que seja possível. As duas primeiras compreendem necessidades primárias e as três últimas secundárias (LIMEIRA, 2009).

Devido a diversos fatores e da complexidade do processo de consumo, seu estudo se fundamenta em uma abordagem multidisciplinar que integre as diversas contribuições das ciências sociais e humanas, como a antropologia, a sociologia, a economia, a psicologia, a história, a semiologia, a comunicação social, entre outras, que, por diversas perspectivas, estudam o comportamento humano.

A renda limitada exige que se façam escolhas com relação aos bens que vão ser comprados, simplesmente porque não se possui renda suficiente para comprar tudo o que se deseja. Outro ponto importante é que ao tomar uma decisão temos objetivos logo se dois produtos custam o mesmo o consumido deve comprar cujo beneficio esperado seja maior. Um bem pode ser substituído por outro, pois nenhum bem é tão precioso a ponto de não estarmos dispostos a abrir mão de certa quantidade dele em troca de quantidades de outros bens.

De acordo com Limeira (2009), existem muitas maneiras alternativas de se satisfazerem os desejos individuais e experiência passada nos ajuda nas decisões já que o acumulo de informações ajuda ao consumidor estando o mesmo a gastar tempo, esforço e dinheiro para levantar informações diretamente relacionadas à aquisição de um bem e aplicará tanto mais recurso para se informar quanto maior for o valor do bem em questão. 
A categoria qualidade possui papel importante neste ambiente. $O$ termo qualidade, conforme Toledo (2013), o empregado de maneira geral sem especificar o aspecto ao qual se refere o atributo qualidade. Ainda se acrescenta a isso que o consumidor Brasileiro tem um tipo de comportamento diferente dos outros países, onde consumir por impulso faz parte do nosso cotidiano (CHEUNG, 2007; LIMEIRA, 2009).

A compreensão das necessidades do consumidor passa a ser fundamental na ampliação da possibilidade de acerto das mudanças pertinentes às relações de causa e efeito que gerenciam a mente humana para a compra de mercadorias, assim como, na ampliação da possibilidade de entendimento da educação desse consumidor ao longo do seu relacionamento com as empresas que comercializam produtos. Logo, em seu comportamento de compra é observado o que influenciará o processo de decisão desta compra.

Em suma, o conhecimento dos meandros do comportamento do consumidor de carne de frango tende a possibilitar a construção de estratégicas na medida em que o comportamento do consumidor é resultado de estímulos de marketing introduzidos: por uma empresa - por meio das características produto, de preço, de promoção e propaganda e de estratégia de distribuição; e pelo ambiente - por meio de fatores econômicos, tecnológicos, políticos, culturais, sociais, pessoais e psicológicas do comprador. Destaca-se ainda que nos mercados de carne verifica-se frequentemente o efeito de substituição, seja entre carnes de espécies diferentes, ou entre cortes de uma mesma espécie (VINNARI, 2008), a questão de segurança do alimento, os impactos ambientais, as formas de produção, ao bem-estar animal e a procedência dos produtos (LATVALA et al., 2012), o que deixa mais desafiador ainda o estudo deste importante segmento de atividade econômica.

\section{METODOLOGIA}

A pesquisa adotou uma abordagem quantitativa do tipo survey. Conforme taxonomia proposta por Vergara (2007), o tipo de pesquisa pode ser definida quanto aos fins e quanto aos meios de investigação. Quanto aos fins, esta investigação classifica-se como explicativa, pois objetiva esclarecer o perfil do comportamento do consumidor final da carne de frango do município de Paragominas no estado do Pará. Para tal, também é descritiva, pois procura identificar aspectos pertinentes às características deste consumidor final. Quanto aos meios, esta investigação é classificada basicamente como pesquisa de campo na medida em que realizou um levantamento de dados junto a consumidores de frango naquele município.

A caracterização da pesquisa está baseada no universo constituído pelos consumidores finais de carne de frango no município paraense de Paragominas que costumam adquirir o produto em açougue, supermercados e outros estabelecimentos comerciais. Paragominas compõe a mesorregião do Sudeste do Estado do Pará e localiza-se a uma latitude $02^{\circ} 59^{\prime} 45^{\prime \prime}$ sul e a uma longitude $47^{\circ} 21^{\prime} 10^{\prime \prime}$ oeste (IBGE, 2013). A área do município é de 19.395,69 km² e sua população foi estimada em 2013 em 103.775 habitantes (IBGE, 2013).

O tipo de pesquisa desenvolvida foi probabilístico, que é aquele em que todos os elementos da população têm probabilidade conhecida, diferente de zero, têm probabilidade de serem incluídos na amostra, o que garante a representatividade da amostra no tocante à população. Este tipo de pesquisa possibilitou a extrapolação de dados para o restante do universo, sendo que a estratificação dos consumidores em classes de renda mensal garantiu a aleatoriedade da amostra. 
As variáveis utilizadas foram: preferência, bens substitutos, frequência de compra, fatores importantes na escolha do ponto de venda, fatores importantes na escolha do produto, qualidade e fatores importantes na escolha. Estas variáveis foram escolhidas na medida em que auxiliam no levantamento de subsídios à proposição de estratégias mercadológicas, pois abordam aspectos relevantes do comportamento de consumo. Parte-se da hipótese de que a capacidade de consumo dos consumidores de frango em Paragominas esteja relacionada com aspectos vinculados a qualidade deste produto.

A investigação foi construída basicamente em três etapas: coleta de dados, tratamento de dados e análise de dados.

a) Coleta de dados: nesta etapa utilizou-se um levantamento bibliográfico e uma pesquisa de campo. A pesquisa bibliográfica foi desenvolvida a partir de bases conceituais vinculadas ao comportamento do consumidor na intenção de aperfeiçoar a compreensão desta temática. Como observa Vergara (2007), a pesquisa bibliográfica é o estudo sistematizado desenvolvido com base em material publicado em livros, revistas, jornais, redes eletrônicas, ou seja, materiais acessíveis ao público em geral. A pesquisa de campo realizou-se junto aos consumidores de carne de frango em Paragominas através da aplicação de questionários que retrataram grupos das seguintes perguntas: local de compra, gosto, preferência, bens substitutos, frequência de compra, fatores importantes na escolha do ponto de venda, fatores importantes na escolha do produto, qualidade e fatores importantes na escolha da carne de frango. Os questionários procuraram fundamentar a pesquisa de maneira quantitativa do tipo survey e foram direcionados para uma amostra de 390 entrevistados domiciliados em Paragominas, sendo 194 pessoas que consomem o produto junto a açougues, 172 pessoas que compram o produto em supermercados e 24 pessoas que adquirem este produto em outros estabelecimentos (normalmente granjas como possível local de compra).

b) Tratamento os dados: nesta etapa foram organizados e sistematizados através de tabelas que forneceram elementos a uma maior compreensão do comportamento do consumidor a partir da utilização dos pontos mais importantes do comportamento deste cliente de carne de frango no município de Paragominas. A etapa de tratamento utilizou como base de cruzamento de dados a renda familiar dos consumidores por meio de cinco níveis de classificação, a saber: Classe "A" - acima de 20 salários mínimos; Classe "B" - entre 10 e 20 salários mínimos; Classe "C" - entre 4 e 10 salários mínimos; Classe "D" - entre 2 e 4 salários mínimos; e Classe "E" - até 2 salários mínimos. A renda familiar foi escolhida como variável na medida em que compõem o perfil da capacidade de consumo das famílias de um modo geral.

Este tratamento de dados ainda contou com uma organização de dados que alicerçou o modelo de análise do teste $\mathrm{G}$. Trata-se de um teste não paramétrico para duas amostras independentes, semelhante em todos os aspectos ao teste Qui quadrado, para dados categóricos dispostos em tabelas de contingência $2 \mathrm{x}$ 2; podendo todavia ser estendido para mais de duas amostras, cada uma com duas ou mais modalidades (AYRES et al., 2007). Observe a seguir a demonstração da equação do teste G: 


$$
\begin{aligned}
& G=2 \sum^{K} F i \quad x \quad \ln \left(\frac{f i}{\hat{f i}}\right) ; \quad g l=k-1 \\
& \text { onde : } \\
& f i=\text { frequência observada ; } \\
& \hat{f i}=\text { frequência esperada ; } \\
& k=\text { número de categorias. }
\end{aligned}
$$

c) Análise de dados: nesta etapa desenvolveu-se um exame crítico sobre o perfil dos consumidores de frango de diferentes faixas de renda quando do momento da compra do produto, de modo ainda a observar a relação entre o poder de consumo e a procura por possíveis requisitos considerados por estes consumidores. Este exame tomou como foco o fornecimento de subsídios a proposições de estratégias mercadológicas para o setor de carnes de frango no município paraense de Paragominas.

\section{RESULTADOS E DISCUSSÕES}

Diante desta investigação, que se propôs a questionar quais aspectos pertinentes ao consumo e às estruturas de comercialização são determinantes no comportamento do consumidor de carne de frango em Paragominas, apresentam-se a seguir seus resultados e discussões.

Inicialmente, estabeleceu-se o cruzamento entre renda familiar e local de compra de frango em Paragominas. Observou-se, através da Tabela 1, que a classe "A" acima de 20 salários mínimos (SM) tem preferência por supermercados tanto nas classes "E" (até 2 SM) e "D"(de 2 a 4 SM) a compra em açougue supera a de supermercado, em detrimento de algumas variáveis desde a proximidade do local de venda. Nos aspectos socioeconômicos da população local, observou-se que a compra em supermercados apenas chegará a superar a compra em açougues nas classes "B"(de 10 a 20 SM) e "C"(de 4 a 10 SM), sendo que a medida que se aumenta a renda, a procura é pelo supermercados. A alternativa "outros" consumidores optaram por maioria a granja como possível local de compra de carne de frango. Destaca-se ainda a relação altamente significativa entre estas variáveis $(0,0009)$.

Tabela 1: Cruzamento entre renda familiar e local de compra, referente ao estudo sobre o mercado de frango em Paragominas (2013).

\begin{tabular}{ccccc}
\hline \multirow{2}{*}{$\begin{array}{c}\text { Renda familiar } \\
\text { (em salários mínimos) }\end{array}$} & Supermercados & Açougues & Outros & Total \\
\cline { 2 - 4 } & 68 & 100 & 12 & 180 \\
\hline Até 2 & 39 & 62 & 13 & 118 \\
2 a 4 & 23 & 17 & 7 & 43 \\
4 a 10 & 18 & 13 & - & 31 \\
10 a 20 & 16 & 2 & - & 18 \\
\hline Acima de 20 & 164 & 194 & 32 & 390 \\
\hline Total & &
\end{tabular}

Fonte: Pesquisa de Campo

$\mathrm{G}=26,848 \mathrm{p}$ valor $=0,0009$ (Altamente Significativa) 
A seguir, apresenta-se, através da Tabela 2, o cruzamento entre renda familiar (em salários mínimos) e frequência de consumo, referente ao estudo sobre o mercado de Frango, realizado no município de Paragominas em 2013.

Tabela 2: Cruzamento entre renda familiar e frequência de consumo, referente ao estudo sobre o mercado de frango em Paragominas (2013).

\begin{tabular}{|c|c|c|c|c|c|c|c|}
\hline \multirow{2}{*}{$\begin{array}{c}\text { Renda familiar } \\
\text { (em salários mínimos) }\end{array}$} & \multicolumn{6}{|c|}{ Frequência do consumidor por semana no local } & \multirow{2}{*}{ Total } \\
\hline & 1 & 2 & 3 & 4 & 5 & 6 & \\
\hline Até 2 & 88 & 43 & 31 & 10 & 3 & 5 & 180 \\
\hline 2 a 4 & 58 & 36 & 13 & 4 & 2 & 5 & 118 \\
\hline 4 a 10 & 21 & 16 & 3 & 2 & 1 & - & 43 \\
\hline 10 a 20 & 23 & 6 & - & 2 & - & - & 31 \\
\hline Acima de 20 & 15 & 2 & - & - & 1 & - & 18 \\
\hline Total & 205 & 103 & 47 & 18 & 7 & 10 & 390 \\
\hline
\end{tabular}

Fonte: Pesquisa de Campo

$\mathrm{G}=34,133 \mathrm{p}$ valor $=0,0252$ (Significativa)

Observa-se que quanto menor a renda do consumidor maior é o número de vezes que o mesmo faz compras ao contrário deste quanto maior é a renda do consumidor menor é o número de vezes que o consumidor faz compras. Os maiores níveis de consumo estão nas classes "D”, que estão na faixa de 2 a 4 salários mínimos, e "E", até 2 salários mínimos. Destaca-se ainda que a relação entre renda familiar (em salários mínimos) e frequência de consumo apresenta-se como significativa $(0,0252)$.

Apresenta-se para análise, por meio da Tabela 3, o cruzamento entre a renda familiar e os fatores importantes na escolha do ponto de venda de frango em Paragominas.

Tabela 3: Cruzamento entre renda familiar e fatores importantes na escolha do ponto de venda de frango em Paragominas (2013).

\begin{tabular}{ccccc}
\hline $\begin{array}{c}\text { Renda familiar } \\
\text { (em salários } \\
\text { mínimos) }\end{array}$ & Qualidade do produto & Higiene do local & Proximidade da residência & Total \\
\cline { 2 - 5 } & 51 & 87 & 42 & 19 \\
Até 2 & 42 & 57 & 5 & 180 \\
2 a 4 & 21 & 17 & - & 43 \\
4 a 10 & 20 & 11 & - & 31 \\
10 a 20 & 14 & 4 & 66 & 18 \\
Acima de 20 & 148 & 176 & & 390 \\
\hline Total & & &
\end{tabular}

Fonte: Pesquisa de Campo

$\mathrm{G}=41,276 \mathrm{p}$ valor $<0,01$ (Altamente Significativa).

Destaca-se que o fator higiene do local é a mais mencionado dentre os entrevistados das classes "D" e "E", enquanto que a proximidade da residência não foi mencionada pelos entrevistados pertencentes a classe "A". A qualidade do produto é preocupação prioritária nas classes "B" e "C". O fator higiene do local possui vínculo direto com o próprio produto comercializado. 
O fator higiene associado à seguridade destes alimentos, de maneira a mencionar a possibilidade de inocuidade dos produtos, ausência de pesticidas e contaminantes, controle das condições de produção, condições de embalagem, distribuição, preservação dos produtos e rastreabilidade (RAIMUNDO, 2013).

A seguir, na Tabela 4, observa-se o cruzamento entre renda familiar e os fatores: atendimento, qualidade de outros produtos, ofertas especiais e possibilidade de comprar outros, em Paragominas.

Tabela 4: Cruzamento entre renda familiar e os fatores: atendimento, qualidade de outros produtos, ofertas especiais e possibilidade de comprar outros (Paragominas - 2013).

\begin{tabular}{cccccc}
\hline & \multicolumn{5}{c}{ FATOR IMPORTANTE } \\
\cline { 2 - 5 } $\begin{array}{c}\text { Renda familiar } \\
\text { (em salários mínimos) }\end{array}$ & Atendimento & $\begin{array}{c}\text { Qualidade de } \\
\text { outros } \\
\text { produtos }\end{array}$ & $\begin{array}{c}\text { Ofertas } \\
\text { especiais }\end{array}$ & $\begin{array}{c}\text { Possibilidade de } \\
\text { comprar outros } \\
\text { produtos }\end{array}$ & Total \\
\hline Até 2 & 77 & 36 & 27 & 40 & 180 \\
2 a 4 & 57 & 23 & 10 & 28 & 118 \\
4 a 10 & 12 & 13 & 4 & 14 & 43 \\
10 a 20 & 10 & 18 & - & 3 & 31 \\
Acima de 20 & 16 & 2 & - & - & 18 \\
\hline Total & $\mathbf{1 7 2}$ & $\mathbf{9 2}$ & $\mathbf{4 1}$ & $\mathbf{8 5}$ & $\mathbf{3 9 0}$ \\
\hline
\end{tabular}

Fonte: Pesquisa de Campo

$\mathrm{G}=50,957 \mathrm{p}$ valor $<0,01$ (Altamente Significativa)

$\mathrm{O}$ atendimento e a qualidade, independente da classe social, são observados como de alta significância, mas é o preço que possui o maior grau de importância na avaliação de demanda do bem, produtos substitutos, a validade no ato da compra do produto e outros. Logo a qualidade do bem é fundamental na escolha do consumo. De acordo com Toledo (2013), o emprego genérico da palavra qualidade para representar coisas distintas deve-se a que, geralmente, o usuário da expressão não explicita a que aspecto se refere o atributo qualidade. Explica ainda que é comum usar-se o termo indistintamente para se referir a produtos, processos, sistema e gerenciamento sem que isso fique explícito.

O cruzamento entre renda familiar e fator importante na escolha do frango pelos consumidores de Paragominas, pode ser verificado na Tabela 5.

Tabela 5: Cruzamento entre renda familiar e fator importante na escolha do produto, referente ao estudo sobre o mercado de frango em Paragominas (2013).

\begin{tabular}{|c|c|c|c|c|c|c|c|}
\hline \multirow[b]{2}{*}{$\begin{array}{c}\text { Renda familiar } \\
\text { (em salários mínimos) }\end{array}$} & \multicolumn{6}{|c|}{ Fator importante na escolha do produto } & \multirow[b]{2}{*}{ Total } \\
\hline & Aparência & Preço & Embalagem & $\begin{array}{l}\text { Tipo de } \\
\text { corte }\end{array}$ & Marca & Validade & \\
\hline Até 2 & 80 & 40 & 10 & 7 & 12 & 31 & 180 \\
\hline 2 a 4 & 47 & 26 & 7 & 6 & 15 & 17 & 118 \\
\hline 4 a 10 & 21 & 10 & 1 & 3 & 2 & 6 & 43 \\
\hline 10 a 20 & 21 & 5 & - & 2 & 1 & 2 & 31 \\
\hline Acima de 20 & 11 & 6 & - & - & 1 & - & 18 \\
\hline Total & 180 & 87 & 18 & 18 & 31 & 56 & 390 \\
\hline
\end{tabular}

Fonte: Pesquisa de Campo

$G=25,901 p$ valor $=0,161$ (Não Significativa) 
O estudo constatou-se que a aparência primeiramente e o preço em seguida, caracteriza o perfil quanto ao fator importante na escolha do produto, em todas as faixas de renda. Registra-se ainda que nas classes "A" e "B", não houve menção aos fatores embalagem. Os consumidores de renda familiar entre 10 a 20 salários mínimos e acima de 20 salários mínimos não mencionaram preocupação com a embalagem curiosamente. Acredita-se que o local de compra chama mais a atenção destes consumidores do que a embalagem.

Através dos consumidores pertencentes às classes sociais estratificadas neste estudo, a Tabela 6 ressalta o cruzamento entre a renda familiar e o tipo do produto comprado com maior frequência, isto é, quanto às partes do frango adquiridas pelos consumidores.

Tabela 6: Cruzamento entre renda familiar e tipo do produto comprado com maior frequência pelos consumidores em Paragominas (2013).

\begin{tabular}{|c|c|c|c|c|c|c|}
\hline \multirow{2}{*}{$\begin{array}{l}\text { Tipo do produto comprado } \\
\text { com maior frequência }\end{array}$} & \multicolumn{5}{|c|}{ Renda familiar (em salários mínimos) } & \multirow{2}{*}{ Total } \\
\hline & Até 2 & 2 a 4 & 4 a 10 & 10 a 20 & $>20$ & \\
\hline Inteiro & 103 & 61 & 21 & 18 & 8 & 211 \\
\hline Peito de frango & 42 & 31 & 16 & 3 & 6 & 98 \\
\hline Coxa e ante coxa & 18 & 14 & 4 & 10 & 3 & 49 \\
\hline Retalho & 14 & 10 & 2 & - & 1 & 27 \\
\hline Subprodutos do frango & 3 & 2 & - & - & - & 5 \\
\hline Total & 180 & 118 & 43 & 31 & 18 & 390 \\
\hline
\end{tabular}

Fonte: Pesquisa de Campo

$\mathrm{G}=21,285 \mathrm{p}$ valor $=0,168$ (Não Significativa)

O cruzamento entre renda familiar e tipo do produto comprado com maior frequência pelos consumidores em Paragominas indica meandros complexos e desafiadores para a compreensão do comportamento do consumidor na medida em que pode haver diferentes preferências referentes a um mesmo produto, isto é, o frango. Assim, o efeito substituição pode se manifestar também entre cortes de uma mesma espécie como bem destaca Vinnari (2008).

Outro cruzamento realizado nesta investigação foi entre a renda familiar e parâmetros de qualidade para o frango em Paragominas. De acordo com a Tabela 7, verificou-se que o parâmetro "cor" avermelhada foi o que obteve grande destaque para os consumidores de todas as classes sociais. A cor tem grande influência no momento do consumidor escolher o produto e também devido ser um parâmetro decisivo, pois tal parâmetro pode ser facilmente observado no momento da compra. 
Tabela 7: Cruzamento entre renda familiar e parâmetros de qualidade para o frango em Paragominas (2013)

\begin{tabular}{ccccc}
\hline \multirow{2}{*}{$\begin{array}{c}\text { Renda familiar } \\
\text { (em salários mínimos) }\end{array}$} & \multicolumn{2}{c}{ Parâmetros de qualidade para o frango } & \multirow{2}{*}{ Total } \\
\cline { 2 - 4 } & Cor & Sabor & Odor & \\
\hline Até 2 & 101 & 45 & 34 & 180 \\
2 a 4 & 65 & 24 & 29 & 118 \\
4 a 10 & 20 & 9 & 14 & 43 \\
10 a 20 & 11 & 19 & 1 & 31 \\
Acima de 20 & 10 & 3 & 5 & 18 \\
\hline Total & $\mathbf{2 0 7}$ & $\mathbf{1 0 0}$ & $\mathbf{8 3}$ & $\mathbf{3 9 0}$ \\
\hline
\end{tabular}

Fonte: Pesquisa de Campo

$G=26,691 p$ valor $<0,01$ (Altamente Significativo)

O segundo parâmetro mais citado pelos consumidores das classes "E" foi o sabor, o primeiro mais citado pela classe "D" 2 a 4 SM e "E" até 2 SM foi a cor, e o segundo parâmetro mais citado pelos consumidores da classe "B" 10 a 20 SM foi o sabor e o da classe "A" acima de 20 SM a cor foi a que mais chamou a atenção dentre os demais. Observam-se com esses resultados que os parâmetros cor e sabor são os que os consumidores consideram mais importantes na escolha da carne do frango. Esse resultado justificase pelo fato desses dois parâmetros poderem ser mais facilmente percebidos pelos consumidores através dos sentidos da visão no momento da compra. Destaca-se aqui que os consumidores que tomam como base o sabor e a cor do frango no momento da compra estão se referindo ao frango comprado pronto para o consumo e não congelado.

Características de grande importância levadas em consideração pelos consumidores na escolha da carne de frango são a cor, sabor e odor. Dessa forma fatores como tipo de embalagem do produto e luminosidade do local onde se comercializa a carne de frango podem influenciar na escolha dos consumidores, haja vista que tais fatores irão influenciar na visão do consumidor no momento da compra. $\mathrm{O}$ odor também influencia diretamente na escolha do produto no momento da compra, pois haverá uma tendência repulsiva ao produto se o mesmo apresentar um odor desagradável. Os fatores que influenciam as escolhas dos consumidores estão basicamente ligados à sua restrição orçamentária e preferências. Destacase o item sobre sabor e maciez em segundo lugar, pois a maioria das classes deu maior importância para esses itens.

A seguir, através das Tabelas 8 e 9, apresenta-se o resultado do cruzamento entre renda familiar e duas estratificações de preferências denominadas: Preferência 1 (em relação ao preparo) e Preferência 2 (em relação ao estado do produto). Primeiramente observa-se o cruzamento entre renda familiar e a Preferência 1(Tabela 8). 
Tabela 8: Cruzamento entre renda familiar e preferência 1 referente ao estudo sobre o mercado de frango em Paragominas (2013)

\begin{tabular}{|c|c|c|c|c|c|c|}
\hline \multirow{2}{*}{$\begin{array}{c}\text { Preferência } 1 \\
\text { (em relação ao preparo) }\end{array}$} & \multicolumn{5}{|c|}{$\begin{array}{c}\text { Renda familiar } \\
\text { (em salários mínimos) }\end{array}$} & \multirow[t]{2}{*}{ Tota } \\
\hline & Até 2 & 2 a 4 & 4 a 10 & 10 a 20 & $>20$ & \\
\hline Por frango assado na brasa & 64 & 56 & 21 & 22 & 9 & 172 \\
\hline Forno industrial & 15 & 9 & 4 & 1 & 6 & 35 \\
\hline Cozido & 65 & 30 & 9 & 5 & 2 & 111 \\
\hline Frito & 36 & 23 & 9 & 3 & 1 & 72 \\
\hline Total & 180 & 118 & 43 & 31 & 18 & 390 \\
\hline
\end{tabular}

Fonte: Pesquisa de Campo

$\mathrm{G}=29,323 \mathrm{p}$ valor $<0,01$ (Altamente Significativo)

A preferência do consumidor por frango cozido se observa no seu comportamento onde é mais frequente na classe "E", tendo em vista que essa é a classe de menor poder aquisitivo, tal preferência pode ser explicada pelo fato do preparo do frango cozido proporcionar melhor aproveitamento da carne além de permitir que outros alimentos sejam adicionados ao frango durante o cozimento.

O tempo de cozimento e a coloração foram os fatores que mais se destacaram na escolha do produto em relação ao momento do preparo, onde o tempo do preparo pode estar associado aos hábitos do consumidor que dispõe pouco tempo para o preparo de suas refeições e a coloração está associada á qualidade de antes do preparo. A seguir, observa-se o cruzamento entre renda familiar e a Preferência 2 (Tabela 9).

Tabela 9: Cruzamento entre renda familiar e preferência 2, referente ao estudo do mercado de frango em Paragominas (2013).

\begin{tabular}{|c|c|c|c|c|}
\hline \multirow{2}{*}{$\begin{array}{c}\text { Renda familiar } \\
\text { (em salários mínimos) }\end{array}$} & \multicolumn{3}{|c|}{$\begin{array}{c}\text { Preferência } 2 \\
\text { (em relação ao estado do produto) }\end{array}$} & \multirow{2}{*}{ Total } \\
\hline & Congelado & Resfriado & $\begin{array}{l}\text { Abatido na } \\
\text { hora }\end{array}$ & \\
\hline Até 2 & 31 & 22 & 127 & 180 \\
\hline 2 a 4 & 40 & 14 & 64 & 118 \\
\hline 4 a 10 & 14 & 9 & 20 & 43 \\
\hline 10 a 20 & 13 & 12 & 6 & 31 \\
\hline Acima de 20 & 6 & 3 & 9 & 18 \\
\hline Total & 104 & 60 & 226 & 390 \\
\hline
\end{tabular}

Fonte: Pesquisa de Campo
$\mathrm{G}=38,724 \mathrm{p}$ valor $<0,01$ (Altamente Significativo)

Verificou-se que a maior parte dos consumidores possui preferência por adquirir o frango abatido na hora, com destaque de preferência para a Classe "E”. Observe na Tabela 10, o cruzamento entre a renda familiar e o tipo de coloração do produto preferido pelo consumidor de frango em Paragominas. Esta dinâmica de conhecimento sobre o comportamento do consumidor reforça a afirmação de Solomon (2016), quando menciona que conhecer o comportamento do consumidor condiciona à organização a adoção da melhor estratégia de marketing, uma vez que a satisfação do cliente deve ser ponto chave. 
Tabela 10: Cruzamento entre renda familiar e tipo de coloração do produto preferido pelos consumidores de frango em Paragominas (2013)

\begin{tabular}{cccccc}
\hline \multirow{2}{*}{$\begin{array}{c}\text { Renda familiar } \\
\text { (em salários mínimos) }\end{array}$} & \multicolumn{3}{c}{ Tipo de coloração de preferência do produto } & \multirow{2}{*}{ Total } \\
\cline { 2 - 5 } & Avermelhada & Bege & Branca & Não sei & \\
\hline Até 2 & 73 & 31 & 53 & 23 & 180 \\
2 a 4 & 34 & 25 & 35 & 24 & 118 \\
4 a 10 & 10 & 15 & 11 & 7 & 43 \\
10 a 20 & 10 & 7 & 5 & 9 & 31 \\
Acima de 20 & 7 & 4 & 5 & 2 & 18 \\
\hline Total & $\mathbf{1 3 4}$ & $\mathbf{8 2}$ & $\mathbf{1 0 9}$ & $\mathbf{6 5}$ & $\mathbf{3 9 0}$ \\
\hline Fonnnnnn
\end{tabular}

Fonte: Pesquisa de Campo

$\mathrm{G}=16,641 \mathrm{p}$ valor $=0,164$ (Não Significativa)

Verifica-se que a tonalidade avermelhada é a mais mencionada pelos entrevistados em todas as faixas de renda pesquisadas. A exceção é a Classe "C", onde a tonalidade bege foi a preferida pelos consumidores.

A seguir, através da Tabela 11, apresenta-se o cruzamento entre a renda familiar e fatores que determinam a escolha da carne de frango em Paragominas.

Tabela 11: Cruzamento entre renda familiar e fatores que determinam a escolha da carne de frango em Paragominas (2013)

\begin{tabular}{cccccc}
\hline \multirow{2}{*}{$\begin{array}{c}\text { Renda familiar } \\
\text { (em salários mínimos) }\end{array}$} & \multicolumn{2}{c}{ Fatores que determinam a escolha da carne de frango } & \multirow{2}{*}{ Total } \\
\cline { 2 - 5 } Maciez & Suculência & Odor & Sabor & \\
\hline Até 2 & 63 & 16 & 18 & 83 & 180 \\
2 a 4 & 40 & 11 & 14 & 53 & 118 \\
4 a 10 & 16 & 6 & 4 & 17 & 43 \\
10 a 20 & 19 & 1 & 1 & 10 & 31 \\
Acima de 20 & 10 & 3 & 1 & 4 & 18 \\
\hline Total & $\mathbf{1 4 8}$ & $\mathbf{3 7}$ & $\mathbf{3 8}$ & $\mathbf{1 6 7}$ & $\mathbf{3 9 0}$ \\
\hline
\end{tabular}

Fonte: Pesquisa de Campo

$\mathrm{G}=15,199 \mathrm{p}$ valor $=0,231$ (Não Significativa).

Dentre os fatores que determinam a escolha da carne de frango, estes não se apresentam como significativos, independentemente dos fatores socioeconômicos. Os dois fatores mais destacados se mantem que são a maciez com 148 e o sabor com 167 dos 390 entrevistados. Ainda se acrescenta que a relação entre as variáveis não se apresentou como significativa $(0,231)$.

O estudo destaca a seguir, por meio da Tabela 12, a preferência dos consumidores da carne de frango em Paragominas (2013), por outros produtos, de acordo com o perfil de renda mensal. 
Tabela 12: Preferência dos consumidores da carne de frango em Paragominas (2013), por outros produtos, de acordo com o perfil de renda mensal.

\begin{tabular}{cccccccc}
\hline \multirow{2}{*}{$\begin{array}{c}\text { Preferência por principais } \\
\text { substitutos da carne de frango }\end{array}$} & \multicolumn{4}{c}{ Renda familiar (em salários mínimos) } & \multirow{2}{*}{ Total } \\
\cline { 2 - 6 } & Até $\mathbf{2}$ & $\mathbf{2}$ a $\mathbf{4}$ & $\mathbf{4}$ a 10 & $\mathbf{1 0}$ a 20 & $\mathbf{2 0}$ & \\
\hline Carne Bovina & 83 & 63 & 27 & 8 & 7 & 188 \\
Suíno & 10 & 6 & 4 & 6 & 1 & 27 \\
Peixe & 79 & 43 & 10 & 17 & 8 & 157 \\
Ovos & 6 & 3 & 2 & - & 1 & 12 \\
Outros & 2 & 3 & - & - & 1 & 6 \\
\hline Total & $\mathbf{1 8 0}$ & $\mathbf{1 1 8}$ & $\mathbf{4 3}$ & $\mathbf{3 1}$ & $\mathbf{1 8}$ & $\mathbf{3 9 0}$ \\
\hline
\end{tabular}

Fonte: Pesquisa de Campo

$\mathrm{G}=22,712 \mathrm{p}$ valor $=0,122$ (Não Significativa)

Ao ir às ruas do município de Paragominas perguntar ao próprio consumidor qual o principal substituto da carne de frango e foi concluído que a independente da classe econômica, o principal substituto é a carne bovina, seguida por peixe e depois carne suína e por fim ovos. Já ao se analisar a preferência por ovos como substitutos constatou-se que não foi significativo, logo o fator socioeconômico não tem apresentado um comportamento diferenciado em comparação às outras classes, pois a substituição do frango por carne bovina e peixe se iguala aos outros.

\section{CONCLUSÃO}

A investigação sobre o comportamento do consumidor final da carne de frango do município de Paragominas se desenvolveu na intenção de contribuir a proposição de estratégias mercadológicas para o setor de carnes de frango naquele município paraense, algo improvável de se realizar se não por meio do conhecimento efetivo e detalhado deste consumidor. O questionamento sobre a percepção do valor no setor de carnes de frango pelos consumidores no município possuiu papel relevante e oportuno nesta discussão.

$O$ estudo constatou que existem inúmeras semelhanças entre os consumidores de frango de diferentes faixas de renda quando estão diante da decisão de compra do produto. Constatou-se uma preferência global pelo frango abatido na hora, que possua coloração avermelhada e comprado em açougues. Entretanto, o estudo aponta resumidamente para a constatação de que quanto maior a renda familiar, que por sua vez determina o poder de consumo do consumidor, maior será a procura pelo quesito qualidade do produto. O que valida a hipótese levantada por este estudo, isto é, a capacidade de consumo dos consumidores de frango em Paragominas está vinculada a aspectos pertinentes a qualidade do produto.

Dentre as limitações deste estudo destacam-se fragilidades pertinentes à reduzida amostra que foi foco de aplicação de questionários. Neste sentido, sugere-se que novas investigações sejam desenvolvidas em direção à produção de carnes relativamente menos comercializadas que a carne bovina e a carne de frango, como, por exemplo, analisar o comportamento do consumidor de carne suína em regiões de alta comercialização deste produto no país, a partir de amostras mais amplas. 


\section{REFERÊNCIAS}

ABPA - Associação Brasileira de Proteína Animal. Relatório anual 2017. Disponível em: http://abpabr.com.br/storage/files/3678c_final_abpa_relatorio_anual_2016_portugues_web_reduzido.pdf. Acessado em: Dez/2017.

AGUIAIS, E. G.; FIGUEIREDO, R. S. Correlação entre consumo de carne de frango e renda no Brasil (2002-2009). Qualia: a ciência em movimento, v. 1, n. 1, p. 64-77, 2015.

AYRES, M; AYRES JR., M; AYRES D.L. e SANTOS, A.S. BioEstat 5.0: Aplicações estatísticas nas áreas de Ciências Biológicas e Médicas. Belém: Sociedade Civil Mamirauá, MCT - CNPq, Conservation International, 2007.

CHEUNG, L. T. Os comportamentos alimentares de brasileiros urbanos: identificação de uma tipologia de consumidores e análise das relações dos grupos com os alimentos. Programa de Engenharia da Produção. 247p. Universidade Federal de São Carlos, 2007 (Tese de Doutorado).

ENGEL, J. F.; BLACKWELL, R. D.; MINIARD, P. Comportamento do consumidor. São Paulo: Thomson, 2005.

FIGUEIREDO JUNIOR, J. P. et al. Caracterização do consumo e perfil do consumidor de frango da cidade de João Pessoa-PB. Revista Agropecuária Técnica, Areia-PB, v. 38, n. 3, p. 153-159, 2017.

GARCIA, E. R. M. et al. Perfil do consumidor de carne de frango no município de Aquidauana, MS. Veterinária e Zootecnia, v. 24, n. 2, p. 345-352, 2017.

IBGE. Instituto Brasileiro de Geografia e Estatística. Populações. Disponível em: http://cidades.ibge.gov.br/xtras/perfil.php?codmun=150550. Acesso: Dez/2016.

KOTLER, Philip. Princípios de marketing. São Paulo: Pearson Prentice Hall, 2007.

LATVALA, T. et al. Diversifying meat consumption patterns: consumers' selfreported past behavior and intentions for change. Meat Science, Oxford, v. 92, p. 71-77, 2012.

LIMEIRA, Tania Maria Vidigal. Comportamento do Consumidor Brasileiro. São Paulo: Saraiva, 2009.

MAZZUCHETTI, R. N. e BATALHA, M. O. O comportamento do consumidor em relação ao consumo e às estruturas de comercialização de carne bovina na região de Amerios-PR. Revista Varia Scientia, v.4 n.8, p.25-43, 2004.

NUNES, C. N. F.; CASTRO, A. M. G. D. O agronegócio do frango: um estudo sobre os consumidores de carne de frango no Triângulo Mineiro. Congresso Virtual Brasileiro, 2007.

OLIVEIRA, A. P. de et al. Caracterização do consumidor de carne de frango em Júlio Borges-PI. Revista Científica de Produção Animal, v. 17, n. 2, p. 129-141, 2015.

PINHEIRO, R. M.; CASTRO, G. C. de; SILVA, H. H.; NUNES, J. M. G. Comportamento do consumidor e pesquisa de mercado. Rio de Janeiro: FGV, 2006.

RAIMUNDO, L. M. B. Comportamento do consumidor de alimentos: uma análise do consumo de carnes em São Paulo. 168p. Universidade Federal de São Carlos, 2013 (Dissertação de Mestrado).

RODRIGUES, F. da S.; LIMA-FILHO, D. de O.; PEREIRA, S. C. F. Estratégias mercadológicas da cadeia agroexportadora de frango de corte do Brasil. In: EnANPAD - Associação Nacional de Pós-Graduação e Pesquisa em Administração. Rio de Janeiro. Setembro de 2008.

SCHIFFMAN, L. G. e KANUK, L. L. Comportamento do consumidor. São Paulo: s/e, 2000.

SHETH, Jagdish N.; MITTAL, Banwari; I. NEWMAN, Bruce. Comportamento do cliente: Indo além do Comportamento do Consumidor. 1.ed. São Paulo: Atlas, 2001.

SOLOMON, M. R. O Comportamento do Consumidor - Comprando, Possuindo e Sendo. São Paulo: Bookman, 2016.

TOLEDO, J. CARLOS de e MASTRANTONIO, S. D. S. A gestão da qualidade em fabricantes de equipamentos para a indústria de alimentos. ENGEVISTA, V. 15, n. 3. p. 313-330, dezembro de 2013.

TONI, D. et al. Influência da imagem e percepção de valor na intenção de compra de carne de frango: um estudo quantitativo. Race, v. 14, n. 3, p. 1005-1034, 2015.

VARGAS, A. R. Comportamento de compra do consumidor no varejo supermercadista: o caso do Mato Grosso. Programa de Engenharia da Produção. Universidade Federal de São Carlos, 2010 (Dissertação de Mestrado).

VERGARA, S. C. Projetos e relatórios de pesquisa em administração. São Paulo: Atlas, 2007.

VELHO, J. P. Disposição dos consumidores porto alegrenses à compra de carne bovina com certificação. Revista Brasileira de Zootecnia. v. 38, n.2 p. 399-404, 2009.

VINNARI, M. The future of meat consumption: expert views from Finland. Technological Forecasting and Social Change [S.I.], v. 75, 2008. 